\title{
Oocyte and embryo cryopreservation - state of art and recent developments in domestic animals*
}

\author{
B. Gajda ${ }^{1}$ and Z. Smorąg \\ National Research Institute of Animal Production, \\ Department of Biotechnology of Animal Reproduction \\ 32-083 Balice, Poland
}

(Received 13 January 2009; revised version 19 March 2009; accepted 24 June 2009)

\begin{abstract}
During the past few decades, significant progress in cryopreservation of mammalian oocytes and embryos has been observed. Transfer of cryopreserved embryos or oocytes resulted in live offspring in at least 25 species. So far, two major methods have been used for oocyte and embryo cryopreservation: conventional slow-rate freezing and vitrification. This review summarizes the progress in cryopreservation of mammalian oocytes and embryos that has been achieved by modifying oocyte/embryo susceptibility to cryopreservation or vitrification technology through such techniques as solid-surface vitrification, cryoloop, microdrop, cryotop, electron microscopy grids, nylon mesh, open pulled straw method or removal of lipids, addition of antifreeze protein or cytoskeletonstabilizing agents, cholesterol or liposomes, centrifugation prior to cryopreservation or application of high hydrostatic pressure. In conclusion, the vitrification method opened new perspectives in cryopreservation of embryos and oocytes, both for in vitro fertilized and somatic nuclear transfer. Authors believe that new cryopreservation procedures which modify the susceptibility of oocytes and embryos to cryopreservation will gain importance as a major tool in mammalian gamete and embryo cryopreservation.
\end{abstract}

KEY WORDS: domestic animal, oocyte, embryo, cryopreservation, vitrification

\section{CRYOPRESERVATION OF OOCYTES AND EMBRYOS: THE STATE OF THE ART}

During the past few decades, significant progress in cryopreservation of mammalian oocytes and embryos has been achieved. Live offspring of at least

\footnotetext{
*Apart of the paper was presented at the Central European Congress of Life Sciences EUROBIOTECH in Krakow, Poland (October 17-19, 2008)

${ }^{1}$ Corresponding author: e-mail: bgajda@izoo.krakow.pl
} 
25 species resulted from transfer of cryopreserved embryos or oocytes. So far, two major methods have been used for oocyte and embryo cryopreservation: conventional slow-rate freezing and vitrification.

Conventional slow freezing was the first system to be used for embryo cryopreservation. In this system, controlled cooling rates allow extracellular and intracellular water exchange without serious osmotic effects or changes in cell shape. This technology has been used successfully to cryopreserve embryos of various species (Dobrinsky, 2002; Fuller and Paynter, 2007). However, unsatisfactory results have been reported for cells more sensitive to chilling, such as oocytes of different species or pig embryos. This can be explained by the decrease in permeability of the cytoplasmic membranes of oocytes during chilling procedure (Ruffing et al., 1993) and relatively high lipid content and/or lipid composition in porcine oocytes and embryos (Nagashima et al., 1994; McEvoy et al., 2000).

An alternative method of cryopreservation is vitrification, which uses a high concentration of cryoprotectant and rapid cooling rates to solidify solutions. Vitrification is a simple technology and it is potentially faster and less expensive than slow freezing. Moreover, it was shown to be more effective than slow freezing for material more sensitive to chilling. It is possible to obtain satisfactory survival rate (79\%) of in vitro produced, vitrified cattle blastocysts, which showed an increased sensitivity to chilling and freezing (Vajta et al., 1996). Although some problems with vitrification remain to be fully addressed before it can become a routine cryopreservation technique, we believe that it shows much promise as a viable alternative to conventional freezing technology.

Cryopreservation of mammalian embryos is now a routine procedure, but considerable differences in efficiency exist depending on the origin of embryos, i.e. whether they are produced in vivo or in vitro, and on the stage of development and species involved.

\section{Embryo source}

Numerous studies indicate that embryos produced in vitro do not survive cryopreservation as well as those produced in vivo (Massip et al., 1995; O'KearneyFlynn et al., 1998). Embryos produced in vitro are sensitive to chilling and freezing as a result of elevated lipid content, which can be modified by culture conditions. Removal of lipids by centrifugation increases their tolerance to chilling and in vitro survival of frozen-thawed embryos is improved after delipidation (Esaki et al., 2004). Reduction of the cytoplasmic lipid content in embryos using the metabolic regulator phenazine ethosulphate (PES) improves the cryotolerance of bovine embryos (Seidel, 2006). In our study on pig embryos produced in vitro 
(Gajda et al., 2008a), we showed a significant decrease in lipid content after in vitro culture in PES supplemented medium.

Embryos cultured with PES also showed an increased ability to survive cryopreservation (Gajda et al., 2008b).

Several authors reported that embryos cultured in medium containing foetal calf serum (FCS) show retarded development and reduced quality (Abe and Hoshi, 2003), as well as reduced susceptibility to cryopreservation as a result of deviation in the relative abundance of developmentally important gene transcripts (Rizos et al., 2003). Studies on bovine embryos (Pugh et al., 1998, 2000) showed that FCS presence during embryo culture reduces their survival after cryopreservation. Those authors suggested that this negative effect is due to an excessive accumulation of lipids in embryos cultured with FCS. It therefore seems advisable to use protein-free media for embryo cryopreservation, or perhaps media with high-molecular-weight synthetic compounds such as polyvinylpyrrolidone (PVP) (Kuleshova et al., 2001), polyvinylalcohol (PVA) (Suzuki and Yoshioka, 2006), ficoll (Kasai et al., 1992; Gajda, 1996; Smorag and Gajda, 1998) and hyaluronic acid (Joly et al., 1992; Palasz et al., 1993, 2008).

Vitrification appears to be preferable to conventional freezing for embryos produced in vitro, and most of the vitrification procedures designed for in vivo embryos have been adapted for in vitro embryos.

\section{Stage of development}

Embryos of different species at the same stage of development, as well as embryos of one species at various stages of development, display significant differences in cryotolerance. In cattle, for example, the survival rate of in vivo and in vitro produced oocytes and embryos is lower when they are cryopreserved at early stages of development than when they are cryopreserved as compacted morulae or blastocysts. Expanded and hatched porcine blastocysts survive better than other embryonic stages (Gajda and Smorag, 2000). The most convenient stage for cryopreservation is the day-7 expanded blastocyst (Han et al., 1994; Hasler et al., 1997; Sommerfeld and Niemann, 1999).

\section{Species}

Cattle. The first calf originated from a frozen embryo was reported in 1973 (Wilmut and Rowson, 1973), and considerable progress has led to improved methods of cryopreservation of embryos produced in vivo. Embryo cryopreservation is an important tool for application of new biotechnologies such as cloning and transgenesis. Embryo freezing has been used in cryopreservation 
and transfer of cloned embryos produced by somatic cell nuclear transfer (Nguyen et al., 2000) and blastomere nuclear transfer (Ushijima et al., 1999), and vitrified cytoplasts have been used in nuclear transfer (Booth et al., 1999). However, survival rates were lower (44\%) for nuclear transferred than for in vitro fertilized embryos (78\%) (Nguyen et al., 2000). In addition, cattle blastocysts injected with DNA have been cryopreserved and transferred, and resulted in pregnancies (Han et al., 2000). Survival rates of DNA-injected blastocysts were affected by freezing and by both the quality ( $78 \%$-excellent, good- $60 \%$, fair- $12 \%)$ and stage of development (early- $48 \%$, mid-52\%, expanded-71\%) of the embryos prior to freezing (Han et al., 2000). Pregnancies have been also produced using cryopreserved bovine blastocysts obtained by intracytoplasmic sperm injection (ICSI) (Keskintepe and Brackett, 2000).

Recently, major efforts have been made to improve the survival rates of in vitro produced embryos after cryopreservation. Compared to in vivo embryos, their IVF counterparts are more sensitive to cryopreservation and produce significantly lower pregnancy rates (less than 50\%) (Agca et al., 1998). Developmental competence of IVF embryos strongly depends on the composition of culture media. However, after transfer, cryopreserved IVP cattle embryos can develop at rates similar to those of non-cryopreserved IVP embryos. Improvement of survival of cryopreserved cattle embryos can be achieved by optimizing culture conditions, selecting best quality embryos based on the kinetics of their development, or changing freezing procedures (Dobrinsky, 2002).

Sheep and goats. Since 1976, a number of studies reported a successful cryopreservation of sheep embryos, resulting in live offspring. First Willadsen et al. (1976), then Moor and Bilton (1977) and finally Smorąg et al. (1977) obtained live lambs following transfer of sheep morulae and blastocysts. The first successful vitrification of ovine embryos was carried out by Gajda et al. (1989). We demonstrated that the survival of transferred vitrified sheep morulae $(60 \%)$ is comparable to that obtained after transfer of embryos frozen using the conventional slow method. In the latter study vitrification was also used to cryopreserve IVP sheep embryos (Ptak et al., 1999). The results of this study show that pregnancy rate for fresh and vitrified blastocysts did not differ significantly (47 vs $42 \%$, respectively) but there were significant differences in lambing rates between the two groups (41 vs $23 \%$, respectively). Although currently vitrification procedure still reduces developmental potential of ovine embryos, its efficiency remains too low for practical applications.

Less information is available in goat. Li et al. (1990) showed that after transfer of frozen-thawed goat early to hatched blastocysts, the pregnancy rate is similar to that observed for fresh embryos. Subsequent work showed that IVP goat embryos can survive cryopreservation (in vitro: $60 \%$, in vivo: $45 \%$ ) and produce live 
offspring after embryo transfer (Tradi et al., 1999).

Surprisingly, small ruminant embryos produced in vivo or in vitro display similar survival rate and developmental competence following cryopreservation and embryo transfer (Dobrinsky, 2002). It should be possible to increase the efficiency of these procedures when the cryopreservation protocols, in majority developed for cattle embryos, are modified to take into account embryo culture and IVP embryo production systems for small ruminants.

Equine embryos. Horse embryos have special characteristics that pose problems for successful freezing. In early equine embryo development (between days 6 and 7), an acellular capsule is formed underneath the zona pellucida which may impair movement of the cryoprotectant into the embryo (Seidel, 1996). Among the factors determining embryo survival after freezing and thawing, the size of the embryo and the developmental stage appear to be more critical than the type of cryoprotectant used. The freezing protocol is similar to that used for bovine embryos, and glycerol is the usual cryoprotectant (Członkowska et al., 1985). Reasonable pregnancy rates of approximately $50 \%$ can be obtained for smaller (less than $250 \mu \mathrm{m}$ in diameter) equine embryos. Pregnancies (40\%) were reported after transfer of vitrified embryos (Hochi et al., 1994). Seidel (1996) used open pulled straw (OPS) vitrification for cryopreserving horse embryos at the morula and blastocyst stages. They hypothesized that a faster cooling rate would improve embryo survival after cryopreservation.

In order for cryopreservation of equine embryos to be as successful as in other domestic animal species, major cellular and molecular breakthroughs in equine embryology are needed in order to facilitate the development of reliable methodologies for equine embryo preservation.

Pig embryos. Intracellular lipids play a major role in the sensitivity of porcine embryos to chilling (Figure 1). This sensitivity seems to correlate with their sensitivity to cryopreservation. This is discussed in more detail in section "Modifying the susceptibility of mammalian oocytes and embryos to cryopreservation" (see pp. 379-381).

Successful cryopreservation of porcine embryos depends on several factors, among them the stage of embryo development, the type of cryoprotectants, and the source of embryos, as well as on the removal of cytoplasmic lipids before cryopreservation. Recently considerable progress has been made in the cryopreservation of pig embryos. Our studies showed that the developmental stage of expanded blastocyst in pig embryos is more suitable for vitrification than the hatched blastocyst stage, and we found that culture of pig embryos in North Carolina State University (NCSU)-23 medium for 6 to 7 days before cryopreservation improves their viability after vitrification in ethylene glycol and ficoll based solution (Gajda and Smorag, 2000, 2002). Transfer of 147 vitrified 
expanded blastocysts into 10 recipients, resulted in birth of 29 live piglets, with pregnancy rate of 50\% (Figure 2; Gajda et al., 2004). Recent application of the OPS method to pig blastocysts has allowed excellent in vitro survival (Berthelot et al., 2000, 2001; Gajda and Smorag, 2001), but pregnancy rates after transfer are quite variable, ranging from zero to $60 \%$ (Gajda et al., 2006).
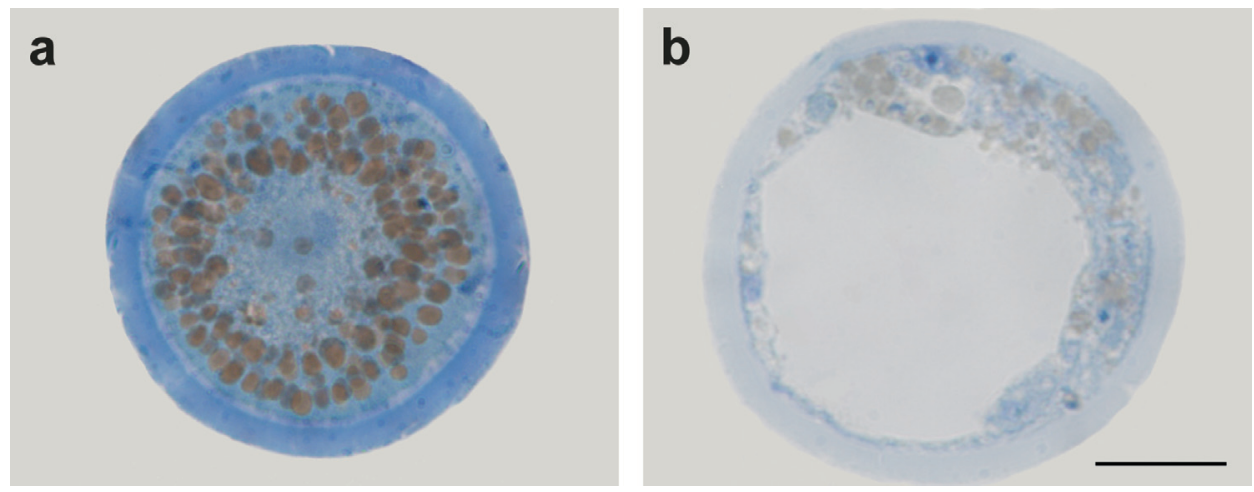

Figure 1. Porcine zygote (a) and blastocyst (b) stained with a mixture of Methylene blue and Azure II, observed under the light microscope. The lipid droplets arranged in the cytoplasm are seen as brown-stained. Scale bar $=35 \mu \mathrm{m}$

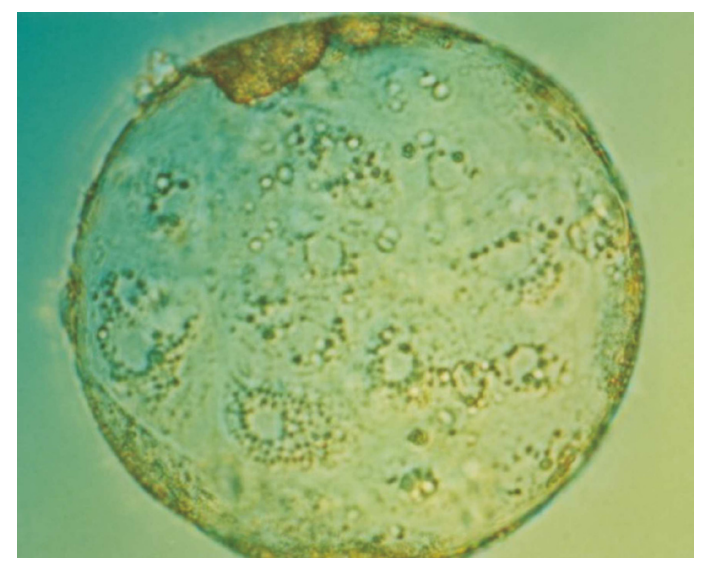

Figure 2. Vitrified-thawed porcine re-expanded blastocyst (original magnification x 100) 


\section{NEW TRENDS IN VITRIFICATION OF OOCYTES AND EMBRYOS}

During the past few years, a significant progress has been made in the cryopreservation of oocytes and embryos of different species using new vitrification methods. Insufficiently rapid cooling rate is believed to be one of the challenges in vitrification process. In order to overcome this problem several methods have been developed like solid surface, cryoloop, microdrop, cryotop, electron microscopy grids or nylon mesh, and open-pulled straws. These methods allow to use of a minimal volume of freezing medium together with an extremely fast cooling rate, which shortens the time spent in the dangerous temperature zone, where sensitivity to chilling can affect the success rate.

Solid-surface vitrification (SSV). High rates of survival and development after solid-surface vitrification have been reported for in vitro matured oocytes from cows (Dinnyes et al., 2000) and goats (Begin et al., 2003). SSV uses a metal surface, precooled to $-180^{\circ} \mathrm{C}$ by partial immersion into liquid nitrogen, to cool microdrops of vitrification solution containing the embryos or oocytes. Recently SSV was used for vitrification of in vitro matured IVM porcine oocytes combined with a cytochalasin B pre-treatment (Somfai et al., 2006). The results indicate that SSV vitrification of IVM porcine oocytes allows the development of latestage preimplantation embryos after parthenogenetic activation. This raises the possibility that SSV oocytes can be used for ICSI or nuclear transfer.

Cryoloop. One of the ultrarapid tools is the cryoloop. This consists of a tiny nylon loop mounted on a small stainless steel tube inserted into the lid of a cryovial. The cryoloop, was first applied to the flash freezing of protein solutions for analysis in crystallography (Parkin and Hope, 1998), and was later used to cryopreserve mammalian embryos and oocytes (Lane et al., 2001), resulting in births from vitrified blastocysts in the case of humans (Makkaida et al., 2001) and monkeys (Makkaida et al., 2003). Nevertheless, despite its successes, the cryoloop is a sensitive and fragile system that may increase the risk of accidental warming (Kuwayama, 2007).

Microdrop vitrification method. This method involves dropping oocytes or embryos containing vitrification solution directly into liquid nitrogen. This method is successful because it eliminates the insulating effect of the container wall. Warming of oocytes is equally rapid when vitrified samples are dropped directly into a warm solution. This method was first proposed by Landa and Tepla (1990) for mouse embryos. It was then successfully used for bovine embryos (Riha et al., 1991), zygotes (Yang and Leibo, 1999), both mature oocytes (Papis et al., 2000) and immature oocytes (Kim et al., 2007), and pig embryos (Misumi et al., 2003). However, no further application of this technology has been published, probably because of the difficulties encountered when handling the embryos. 
Cryotop (also called minimum-volume cooling). The cryotop has proven to be an easy and practical vitrification technique with extremely high cooling and warming rates. In this method, most of the vitrification solution can be removed after embryo loading, and therefore, the volume immersed directly into liquid nitrogen is extremely low. Embryos may pass rapidly through the dangerous zone (temperature range from +20 to $-20^{\circ} \mathrm{C}$ ), which decreases the risk of chilling injury. This method has been applied to various species for embryo cryopreservation, including the cow (Chian et al., 2004), rabbit (Hochi et al., 2004), buffalo (Muenthaisong et al., 2007), pig (Du et al., 2007) and human (Antinori et al., 2007).

Electron microscopy grids and nylon mesh. Alternative methods involving electron microscope (EM) grids, thin-walled open-pulled straws (OPS) or nylon mesh allow direct contact between embryos containing medium and liquid nitrogen that increases cooling and warming rates. These containers require less than 1-2 $\mu 1$ of an embryo suspension. However, the number of samples per container is restricted to 10-15 for EM grids and 4-6 for OPS (Martino et al., 1996; Matsumoto et al., 2001). Therefore, these methods are not suitable for vitrification of large numbers of oocytes or embryos. A membrane filter is useful for vitrifying large numbers of bovine oocytes. However, a bigger pore size is helpful for decreasing the volume of solution containing oocytes, which is the case with the EM grid (55 $\mu \mathrm{m}$ mesh size) and nylon mesh (60 $\mu \mathrm{m}$ mesh size). The EM grid has been used for vitrification of bovine cumulus-oocyte complexes (COCs) (Martino et al., 1996), bovine blastocysts (Park et al., 1999), and human zygotes (Park et al., 2000); nylon mesh may be applicable to other mammalian oocytes and embryos (Matsumoto et al., 2001; Abe et al., 2005). Given that a nylon mesh can easily handle a large number of oocytes or embryos, using this holder for the vitrification of GV bovine oocytes, for example, should facilitate gamete storage for further application in assisted reproductive technologies, such as in vitro fertilization, cloning, and stem cell biology.

Open Pulled Straw (OPS) method. Another method of vitrification is the open pulled straw method. In this method a standard plastic straw $(0.25 \mathrm{ml})$ has previously been heat-pulled to half the diameter and thickness of the wall. The embryos in minimum volume of the vitrification solution $(>0.1 \mu \mathrm{l})$ are loaded by the capillary effect into the end of the straw. The straws are then immersed directly into liquid nitrogen allowing direct contact between the two solutions. Upon warming, the end of the straw is immersed into the medium, allowing the rapid dilution of cryoprotectant solution. The OPS method offers several advantages: extremely fast cooling and warming rates of more than $20000^{\circ} \mathrm{C} / \mathrm{min}$, brief contact with concentrated cryoprotective additives (less than $30 \mathrm{sec}$ over a range of $130^{\circ} \mathrm{C}$ ), and the possibility of avoiding injury due to chilling and of decreasing 
toxic and osmotic damage. With the introduction of the open pulled straw in 1997, the successful vitrification of embryos and oocytes from several different species have been reported: early stage bovine embryos produced in vitro (Vajta et al., 1997a), morula and blastocyst of pig (Berthelot et al., 2000; Gajda et al., 2006), horse (Oberstein et al., 2001) and cow (Hyttel et al., 2000), and porcine oocytes (Vajta et al., 1997b). Using this technique calves have been born following the transfer of embryos vitrified at both the oocyte and blastocyst stages (Vajta et al., 1999; Le Gal et al., 2000). In this way, OPS vitrification offers a new way to solve basic problems of reproductive cryobiology, and it may have a practical impact on animal biotechnology and assisted reproduction in humans.

\section{MODIFYING THE SUSCEPTIBILITY OF MAMMALIAN OOCYTES AND EMBRYOS TO CRYOPRESERVATION}

Important advances have been made in cryopreserving oocytes and embryos by modifying their susceptibility to the procedure. The techniques applied include removal of lipids, addition of antifreeze protein or cytoskeleton-stabilizing agents, addition of cholesterol or liposomes, centrifugation prior to cryopreservation, or application of high hydrostatic pressure.

Microsurgical removal of lipid compounds. As already mentioned, the lipid content of pig embryos is relatively high and decreases as the embryo develops. This high lipid concentration makes pig embryos, especially those at early stages of development, exceptionally sensitive to cryopreservation. Freezing pig embryos that are at the 2- to 8-cell stage and from which lipids have been microsurgically removed (Nagashima et al., 1994) makes them more susceptible to cryopreservation. In that study, in vitro development to the blastocyst stage was observed after thawing, and complete in vivo development and normal offspring after transplantation were obtained. The study also found that the delipidated embryos survived cryopreservation regardless of whether they were frozen immediately after lipid removal or after a brief culturing period. In contrast, no control embryo survived the freezing process. This study was the first to show directly that the high lipid content of pig embryos has a negative effect on the susceptibility of embryos to cryopreservation. Another study (Dobrinsky, 1999) found that delipidated pig embryos at more advanced stages of development (morula/early blastocyst) show a much higher survival rate than do embryos with intact lipids. Other work confirmed that both frozen and vitrified pig embryos from which lipids have been micro-surgically removed can develop fully in vivo (Nagashima et al., 1995). A study with vitrified pig oocytes showed that after microsurgical removal of lipids, the oocytes can be efficiently fertilized in vitro 
and can develop to the stage of the 8-cell and morula (Nagashima et al., 1996). Although the microsurgical removal of lipids from embryos considerably improves cryopreservation efficiency, the method is not suitable for practical application because it is time-consuming.

Non-invasive removal of lipids. Recently, an alternative non-invasive delipidation method has been reported. This method does not require micromanipulation and it depends on partial digestion of the zona pellucida, which allows full separation of lipids during centrifugation. The non-invasive delipidation method has been successfully used for cryopreservation of in vitro pig morula (Esaki et al., 2004), oocytes (Du et al., 2006) and cloned blastocysts (Nakayama et al., 2008).

Addition of antifreeze protein. Injection of antifreeze proteins (AFPs) into embryos can improve the success of cryopreservation, since they inhibit the growth of ice crystals as well as the recrystallization of water during thawing. These antifreeze proteins are naturally expressed in sub-arctic fish species whose embryos show greater tolerance to freezing. Moreover, they can protect cell membranes from cold-induced damage (Rubinsky et al., 1991) and inhibit ice recrystallization (Knight et al., 1984). The protective effect of antifreeze protein depends on the concentration and type of AFP used. Recent studies have shown that AFP can protect embryos from chilling, and that this effect may be due to stabilization of the cellular membranes during chilling rather than to inhibition of ice crystal formation (Robles et al., 2007). Further experiments are needed to determine the effect of the addition of antifreeze protein on embryo cryosurvival and chilling resistance.

Addition of cytoskeleton-stabilizing agents. One possibility to increase the efficiency of pig embryo cryopreservation is to add agents that stabilize cytoskeleton structure in embryos, because it is known that it may be damaged by the cryopreservation process. Agents known to stabilize cytoskeleton structure include cytochalasin B, cytochalasin D and colchicine (Dobrinsky, 1996). Dobrinsky et al. (1997, 2000), who investigated the effect of cytochalasin B on depolarization of microfilaments and the efficiency of pig embryo vitrification, found that this factor increases on in vitro and in vivo survival of vitrified expanding and hatching blastocysts. In contrast, no improvement in survival was observed for morulae/early blastocysts. Cell analysis under a confocal microscope revealed considerable cytoskeleton damage in vitrified embryos not treated with cytochalasin B, whereas vitrified embryos treated with a stabilizing agent showed mostly normal repolarization of microfilaments and other cytoskeleton components. These observations are evidence that cryopreservation may affect the cytoskeleton and that microfilament depolarization before vitrification considerably increases embryo survival after vitrification (Dobrinsky, 1999). 
Addition of cholesterol or liposomes. Attempts to modify culture media for bovine embryos obtained after in vitro fertilization and then cryopreserved in a medium supplemented with liposomes containing lecithin, sphingomyelin and cholesterol were carried out by Pugh et al. (1998). It was found that the liposome supplement had no negative effect on the development of embryos to the blastocyst stage or on their survival after thawing, whereas the presence of lecithin in liposomes reduced the survival of cryopreserved bovine embryos, which may suggest that lecithin has an adverse effect on changes in cell membrane composition.

Horvarth and Seidel (2006) increased the proportion of cleaving embryos that developed to the 8-cell stage, by adding cholesterol to the oocyte cryopreservation medium before vitrification, followed by in vitro fertilization. However, this study shows that, although significant improvement in post-thaw oocyte viability and early cleavage was observed after addition of cholesterol, blastocysts rates remained comparable to those derived from non-treated cryopreserved oocytes.

Centrifugation prior to cryopreservation. Polarization of lipid droplets as a result of centrifugation is a good method for visualizing pronuclei in pig zygotes. Moreover, lipids polarized by centrifugation can be mechanically removed, which makes pig embryos at early stages of development more susceptible to cooling and cryopreservation. On the other hand, centrifugation without lipid removal may affect the survival and developmental competence of frozen mature oocytes. Otoi et al. (1997) found that although centrifugation has a negative effect on bovine oocytes, its use is advantageous in the context of cryopreservation. A recent study with pig oocytes and embryos (Somfai et al., 2008) showed that centrifugation (10 $000 \mathrm{~g}$ for $20 \mathrm{~min}$ ) reduced the rate of surviving vitrified oocytes, although the proportion of parthenogenetic divisions was similar in the group of centrifuged and non-centrifuged oocytes (42 and 47\%, respectively). Meanwhile, although zygote centrifugation slightly improves their survival after cryopreservation, it does not increase the developmental competence of surviving zygotes. Thus, those authors suggested that centrifugation should be used before vitrification only to separate monospermic zygotes from polyspermic ones, which may increase the efficiency of their cryopreservation.

Application of high hydrostatic pressure. The possibility of using high hydrostatic pressure (300-800 bar) to increase cryopreservation efficiency for pig gametes and embryos was first demonstrated by Pribenszky et al. (2005a,c) and $\mathrm{Du}$ et al. (2008). Those authors suggested that, sublethal environmental stress, induced, for example, by high pressure, increases concentration of specific chaperone proteins in gametes and embryos. Synthesis of these proteins results in an increased tolerance of cells to stress induced by treatments such as cryopreservation or culture in vitro, which, in turn, increases the efficiency of the above biotechnological procedure. Cell treatment with elevated hydrostatic 
pressure was successfully used for cryopreservation of boar spermatozoa (Pribenszky et al., 2005a; Kuo et al., 2007), vitrification of pig oocytes (Du et al., 2008; Pribenszky et al., 2008), and vitrification of bovine blastocysts obtained in vitro (Pribenszky et al., 2005b, 2007).

\section{CONCLUSIONS}

In the near future, use of cryopreserved embryos will be a routine alternative for breeding programmes in most domestic animal species, but the technology should be improved. The vitrification method opened new perspectives in cryopreservation of embryos and oocytes, both for in vitro fertilization and somatic cell nuclear transfer procedures. By its technical potential, this method creates a substantial improvement of the efficiency of cryopreservation. We believe that new cryopreservation procedures which modify the susceptibility of oocytes and embryos to low temperature will gain importance as a major tool in mammalian gamete and embryo cryopreservation.

\section{ACKNOWLEDGEMENTS}

The Figure 1 presented in the article was donated by my colleague Dr. Marek Romek from the Institute of Zoology, Jagiellonian University in Krakow (Poland).

\section{REFERENCES}

Abe Y., Hara K., Matsumoto H., Kobayashi J., Sasada H., Ekwall H., Rodriguez-Martinez H., Sato E., 2005. Feasibility of a nylon-mesh holder for vitrification of bovine germinal vesicle oocytes in subsequent production of viable blastocysts. Biol. Reprod. 72, 1416-1420

Abe H., Hoshi H., 2003. Evaluation of bovine embryos produced in high performance serum-free media. J. Reprod. Fertil. 49, 193-202

Agca Y., Monson R.L., Northey D.L., Peschel D.E., Schaefer D.M., Rutledge J.J., 1998. Normal calves from transfer of biopsied, sexed and vitrified IVP bovine embryos. Theriogenology 50 , 129-145

Antinori M., Licata E., Dani G., Cerusico F., Versac I.C., Antinori S., 2007. Cryotop vitrification of human oocytes results in high survival rate and healthy deliveries. Reprod. Biomed. (Online) $14,72-79$

Begin I., Bhatia B., Baldassare H., Dinnyes A., Keefer C.L., 2003. Cryopreservation of goat oocytes and in vitro derived 2-4 cell embryos using the cryoloop (CLV) and solid-surface vitrification (SSV) methods. Theriogenology 59, 1839-1850 
Berthelot F., Martinat-Botte F., Locatelli A., Perreau C., Terqui M., 2000. Piglets born after vitrification of embryo using the open pulled straw method. Cryobiology 41, 116-124

Berthelot F., Martinat-Botte F., Perreau C., Terqui M., 2001. Birth of piglets after OPS vitrification and transfer of compacted morula stage embryos with intact zona pellucida. Reprod. Nutr. Develop. 41, 267-272

Booth P.J., Vajta G., Hoj A., Holm P., Jacobsen H., Greve T., Callesen H., 1999. Full-term development of nuclear transfer calves produced from open-pulled straw (OPS) vitrified cytoplasts: Work in progress. Theriogenology 51, 999-1006

Chian R.C., Kuwayama M., Tan L., Tan J., Kato O., Nagai T., , 2004. High survival rate of bovine oocytes matured in vitro following vitrification. J. Reprod. Develop. 50, 685-696

Członkowska M., Boyle M.S., Allen W.R., 1985. Deep freezing of horse embryos. J. Reprod. Fert. 75, 485-490

Dinnyes D., Dai Y., Jiang S., Yang X., 2000. High developmental rates of vitrified bovine cumulus oocytes following parthenogenetic activation, in vitro fertilization, and somatic cell nuclear transfer. Biol. Reprod. 63, 513-518

Dobrinsky J.R., 1996. Cellular approach to cryopreservation of embryos. Theriogenology 45, 1726

Dobrinsky J.R., 1999. Cryopreservation of swine embryos: Production for the future. Embryo Transfer Newsletter 11, 18-23

Dobrinsky J.R., 2002. Advancements in cryopreservation of domestic animal embryos. Theriogenology 57, 285-302

Dobrinsky J.R., Long C.R., Johnson L.A., 1997. Stability of microfilaments during swine embryos cryopreservation. Theriogenology 47, 343 (Abstr.)

Dobrinsky J.R., Pursel V.G., Long C.R., Johnson L.A., 2000. Birth of piglets after transfer of embryos cryopreserved by cytoskeletal stabilization and vitrification. Biol. Reprod. 62, 564570

Du Y., Kragh P.M., Zhang X., Yang H., Vajta G., Bolund L., 2006. Successful vitrification of parthenogenetic porcine blastocysts produced from delipated in vitro-matured oocytes. Reprod. Fert. Develop. 18, 153 (Abstr.)

Du Y., Li J., Kragh P.M., Zhang Y. et al., 2007. Piglets born from vitrified cloned blastocysts produced with a simplified method of delipation and nuclear transfer. Cloning Stem Cell. 9, 469-476

Du Y., Pribenszky Cs., Molnar M., Zhang X., Yang H., Kuwayama M., Pedersen A.M., Villemoes K., Bolund L., Vajta G., 2008. High hydrostatic pressure (HHP): a new way to improve in vitro developmental competence of porcine matured oocytes after vitrification. Reproduction 135, $13-17$

Esaki R., Ueda H., Kurome M., Hirakawa K., Tomii R., Yoshioka H., Ushijima H., Kuwayama M., Nagashima H., 2004. Cryopreservation of porcine embryos derived from in vitro-matured oocytes. Biol. Reprod. 71, 432-437

Fuller B.J., Paynter S.J., 2007. Cryopreservation of mammalian embryos. Methods Mol. Biol. 368, 325-329

Gajda B., 1996. Vitrification of rabbit embryos at 1-cell to morula stage in an ethylene glycol-based solution. Cryo-Lett. 17, 363-370

Gajda B., Romek M., Krzysztofowicz E., Smorag Z., 2008a. Evaluation of lipid content in porcine embryos cultured in modified conditions. Reprod. Domest. Anim. 43, Suppl. 3, 116-117

Gajda B., Smorag Z., 2000. Survival of pig morula and blastocyst after exposure to vitrification media or vitrification. Cryo-Lett. 21, 231-236 
Gajda B., Smorag Z., 2001. Effectiveness of vitrified porcine embryos depending on cryopreserved sample volume (in Polish). Proceedings of II Meeting of Polish Society of Reproductive Biology, Warsaw, P-IV-4

Gajda B., Smorag Z., 2002. Vitrification of cultured and non-cultured expanded and hatched blastocysts. Cryo-Lett. 23, 385-388

Gajda B., Smorag Z., Bryła M., 2008b. Effect of phenazine ethosulfate on porcine blastocysts development, apoptosis, and cryotolerance after open pulled straw vitrification. Reprod. Fert. Develop. 20, 118, Abstr. 75

Gajda B., Smorag Z., Wieczorek J., 2004. Piglets obtained after transplantation of vitrified blastocysts (in Polish). Med. wet. 60, 371-373

Gajda B., Smorąg Z., Wieczorek J., 2006. Successful cryopreservation of porcine embryos using a minimum volume of vitrification solution. Acta Biol. Cracov., Ser. Zool. 48, Suppl. 1, 44

Gajda B., Smorag Z., Wierzbowski S., Jura J., Wieczorek B., 1989. Transfer of vitrified sheep morula. Zuchthyg. 24, 97-100

Han Y.M., Kim S.H., Park J.S. et al., 2000. Blastocyst viability and generation of transgenic cattle following freezing of in vitro produced, DNA-injected embryos. Anim. Reprod. Sci. 63, 53-63

Han Y.M., Yamashina H., Koyama N., Lee K.K., Fukui Y., 1994. Effects of quality and developmental stage on the survival of IVF-derived bovine blastocysts cultured in vitro after freezing and thawing. Theriogenology 42, 645-654

Hasler J.F., Hurtgen P.J., Jin Z.Q., Stokes J.E., 1997. Survival of IVF derived bovine embryos frozen in glycerol or ethylene glycol. Theriogenology 48, 563-579

Hochi S., Fujimoto T., Braun J., Oguri N., 1994. Pregnancies following transfer of equine embryos cryopreserved by vitrification. Theriogenology 42, 483-488

Hochi S., Terao T., Kamei M., Kato M., Hirabayashi M., Hirao M., 2004. Successful vitrification of pronuclear-stage rabbit zygotes by minimum volume cooling procedure. Theriogenology 61 , 267-275

Horvath G., Seidel Jr. G.E., 2006. Vitrification of bovine oocytes after treatment with cholesterolloaded methyl-beta-cyclodextrin. Theriogenology 66, 1026-1033

Hyttel P., Vajta G., Callesen H., 2000. Vitrification of bovine oocytes with the Open Pulled Straw method: ultrastructural consequences. Mol. Reprod. Dev. 56, 80-88

Joly Th., Nibart M., Thibier M., 1992. Hyaluronic acid as substitute for proteins in the deep-freezing of embryos from mice and sheep: an in vitro investigation. Theriogenology 37, 473-480

Kasai M., Nishimori M., Zhu S.E., Sakurai T., Machida T., 1992. High survival of rabbit morulae after vitrification in an ethylene glycol-based solution by a simple method. Biol. Reprod. 46, 1042-1046

Keskintepe L., Brackett B.G., 2000. Cryopreservation of bovine blastocysts obtained by intracytoplasmic sperm injection. Theriogenology 53, 1041-1052

Kim D.H., Park H.S., Kim S.W. et al., 2007. Vitrification of immature bovine oocytes by the microdrop method. J. Reprod. Develop. 53, 843-851

Knight C.A., DeVries A.L., Oolman L.D., 1984. Fish antifreeze protein and the freezing and recrystallization of ice. Nature 308, 295-296

Kuleshova L.L., Shaw J.M., Trounson A.O., 2001. Studies on replacing almost of the penetrating cryoprotectant by polymers for embryo cryopreservation. Cryobiology 43, 21-31

Kuo Y.H., Pribenszky Cs., Huang S.Y., 2007. High litter size is achieved by the insemination of high hydrostatic pressure-treated frozen thawed boar semen. In: Proceedings of $6^{\text {th }}$ International Conference on Boar Semen Preservation. Allison, Ontario (Canada), p. III, 22

Kuwayama M., 2007. Highly efficient vitrification for cryopreservation of human oocytes and embryos: The Cryotop method. Theriogenology 67, 73-80 
Landa V., Tepla O., 1990. Cryopreservation of mouse 8-cell embryos in microdrops. Folia Biol. Prague 6, 153-158

Le Gal F., De Roover R., Verhaeghe B., Etienne D., Massip A., 2000. Birth of calves from vitrified oocytes. Ann. Med. Vet. 144, 33-36

Li R., Cameron A.W.N., Batt P.A., Trounson A.O., 1990. Maximum survival of frozen goat embryos is attained at the expanded, hatching and hatched blastocyst stages of development. Reprod. Fert. Develop. 2, 345-350

Makkaida T., Nakamura S., Tomiyama T., Wada S., Kasai M., Takahashi K., 2001. Successful birth after transfer of vitrified human blastocysts with use of a cryoloop containerless technique. Fert. Steril. 76, 618-620

Makkaida T., Takahashi K., Kasai M., 2003. Blastocyst cryopreservation: ultra-rapid vitrification using cryoloop technique. Reprod. Biomed. (Online) 6, 221-225

Martino A., Songasen N., Leibo S.P., 1996. Development into blastocysts of bovine oocytes cryopreserved by ultra-rapid cooling. Biol. Reprod. 54, 1059-1069

Massip A., Mermillod P., Dinnyes A., 1995. Morphology and biochemistry of in vitro produced bovine embryos: implication for their cryopreservation. Hum. Reprod. 10, 3004-3011

Matsumoto H., Jiang J.Y., Tanaka T., Sasada H., Sato E., 2001. Vitrification of large quantities of immature bovine oocytes using nylon mesh. Cryobiology 42, 139-144

McEvoy T.G., Coull G.D., Broadbent P.J., Hutchinson S.M., Speake B.K., 2000. Fatty acid composition of lipids in immature cattle, pig and sheep oocytes with intact zona pellucida. J. Reprod. Fertil. 118, 163-170

Misumi K., Suzuki M., Sato S., Saito N., 2003. Successful production of piglets derived from vitrified morulae and early blastocysts using a microdroplet metod. Theriogenology 60, 253-260

Moor N.W., Bilton R.J., 1977. Frozen and storage of embryos of farm animals: progress and implication. In: K. Elliot, J. Whelan (Editors). The Freezing of Mammalian Embryos. Ciba Foundation Symposium 52. Elsevier, Amsterdam, pp. 203

Muenthaisong S., Laowtammathron C., Ketudat-Cairns M., Parnpai R., Hochi S., 2007. Quality analysis of buffalo blastocysts derived from oocytes vitrified before or after enucleation and reconstructed with somatic cell nuclei. Theriogenology 67, 893-900

Nagashima H., Kashiwazaki N., Ashman R.J., Grupen C.G., Nottle M.B., 1995. Cryopreservation of porcine embryos. Nature 374,416

Nagashima H., Kashiwazaki N., Ashman R.J., Grupen C.G., Seamark R.F., Nottle M.B., 1994. Removal of cytoplasmic lipid enhances the tolerance of porcine embryos to chilling. Biol. Reprod. 51, 618-622

Nagashima H., Kuwayama M., Grupen C.G., Ashman R.J., Nottle M.B., 1996. Vitrification of porcine early cleavage stage embryos and oocyte after removal of cytoplasmic lipid droplets. Theriogenology 45, 180 (Abstr.)

Nakayama N., Tomii R., Ueno S., Matsunari H., Saitio H., Ogawa B., Nagashima H., 2008. Production of cloned piglets from nuclear transfer embryos after vitrification. Reprod. Fert. Develop. 20, 123 (Abstr.)

Nguyen B.X., Sotomaru Y., Tani T., Kato Y., Tsunoda Y., 2000. Efficient cryopreservation of bovine blastocysts derived from nuclear transfer with somatic cells using partial dehydration and vitrification. Theriogenology 53, 1439-1448

Oberstein N., O’Donovan M.K., Bruemmer J.E., Seidel Jr. G.E., Carnevale E.M., Squires E.L., 2001. Cryopreservation of equine embryos by open pulled straw, cryoloop, or conventional slow cooling methods. Theriogenology 55, 607-613

O’Kearney-Flynn M., Wade M., Duffy P., Gath V., Boland M.P., Dobrinsky J.M., 1998. Effect of cryopreservation on IVP cattle embryos development in vitro and in vivo. Theriogenology 49, 178 (Abstr.) 
Otoi T., Yamamoto K., Koyama N., Tachikawa S., Muraki M., Kikkawa Y., Suzuki T., 1997. Cryopreservation of mature bovine oocytes following centrifugation treatment. Cryobiology 34, $36-41$

Palasz A., Alkemade S., Mapletoft R.J., 1993. The use of sodium hyaluronate in freezing media for bovine and murine embryos. Cryobiology 30, 172-178

Palasz A.T., Beltran Brena P., Martinem M.F., Perez-Garnelo S.S., Ramirez M.A., Gutierez-Adan A., De La Fuente J., 2008. Development, molecular composition and freeze tolerance of bovine embryos cultured in TCM-199 supplemented with hyaluronan. Zygote 16, 39-47

Papis K., Shimizu M., Izaike Y., 2000. Factors affecting the survivability of bovine oocytes vitrified in droplets. Theriogenology 54, 651-658

Park S.P., Kim E.Y., Kim D.I., Park N.H., Won Y.S., Yoon S.H., Chung K.S., Lim J.H., 1999. Simple, efficient and successful vitrification of bovine blastocysts using electron microscopic grid. Hum. Reprod. 14, 2838-2843

Park S.P., Kim Y.E., Oh J.H., Nam H.K., Lee K.S., Park S.Y., Park E.M., Yoon S.H., Chung K.S., Lim J.H., 2000. Ultrarapid freezing of human multipronuclear zygotes using electron microscope grids. Hum. Reprod. 15, 1787-1790

Parkin S., Hope H., 1998. Macromolecular crystallography: cooling, mounting, storage and transportation of crystals. J. Appl. Cryst. 31, 945-953

Pribenszky Cs., Du Y., Molnar M., Harnos A., Vajta G., 2008. Increased stress tolerance of matured pig oocytes after high hydrostatic pressure treatment. Anim. Reprod. Sci. 106, 200-207

Pribenszky Cs., Molnar M., Cseh S., Solti L., 2005a. Improving post-thaw survival of cryopreserved mouse blastocysts by hydrostatic pressure challenge. Anim. Reprod. Sci. 87, 143-150

Pribenszky Cs., Molnar M., Horvarth A., Harnos A., Szenci O., 2005c. Hydrostatic pressure induced increase in post-thaw motility of frozen boar spermatozoa. Reprod. Fert. Develop. 18, 162-163

Pribenszky Cs., Molnar M., Ulrich P., Keiko L., 2005b. Improving the post thaw survival of cryopreserved IVF bovine blastocysts by hydrostatic pressure challenge. Reprod. Domest. Anim. 40, 338 (Abstr.)

Pribenszky Cs., Siquiera E., Molnar M., Rumpf R., 2007. Improved post-warming developmental competence of open pulled straw-vitrified in vitro-produced bovine blastocysts by sublethal hydrostatic pressure pretreatment. Reprod. Fert. Develop. 20, 125 (Abstr.)

Ptak G., Dattena M., Loi P., Tischner M., Cappai P., 1999. Ovum pick-up in sheep: Efficiency of in vitro embryo production, vitrification and birth of offspring. Theriogenology 52, 1105-1114

Pugh P.A., Ankersmit A.E., McGowan L.T., Tervit H.R., 1998. Cryopreservation of in vitro-produced bovine embryos: effects of protein type and concentration during freezing or of liposomes during culture on post-thaw survival. Theriogenology 50, 495-506

Pugh P.A., Tervit H.R., Niemann H., 2000. Effects of vitrification medium composition on the survival of bovine in vitro produced embryos, following in straw-dilution, in vitro and in vivo following transfer. Anim. Reprod. Sci. 58, 9-22

Riha J., Landa V., Kneissl J., Matus J., Jindra J., Kloucek Z., 1991. Vitrification of cattle embryos by direct dropping into liquid nitrogen and embryo survival after nonsurgical transfer. Živoc. Vyr. 36, 113-119

Rizos D., Gutierrez-Adan A., Perez-Garnelo S., De La Fuente J., Boland M.P., Lonergan P., 2003. Bovine embryo culture in the presence or absence of serum: implication for blastocyst development, cryotolerance, and messenger RNA expression. Biol. Reprod. 68, 236-243

Robles V., Barbosa V., Herraez M.P., Martinez-Paramo S., Cancela M.L., 2007. The antifreeze protein type I (AFP I) increases seabream (Sparus aurata) embryos tolerance to low temperatures. Theriogenology 68, 284-289 
Rubinsky B., Arav A., Fletcher G.L., 1991. Hypothermic protection: a fundamental property of antifreeze proteins. Biochem. Biophys. Res. Commun. 180, 566-571

Ruffing N.A., Steponkus P.L., Pitt R.E., Parks J.E., 1993. Osmometric behaviour, hydraulic conductivity, and incidence of intracellular ice formation in bovine oocytes at different developmental stages. Cryobiology 30, 562-580

Seidel G.E., 1996. Cryopreservation of equine embryos. Vet. Clin. N. Amer.-Equine Pract. 12, 85-99

Seidel Jr. G.E., 2006. Modifying oocytes and embryos to improve their cryopreservation. Theriogenology 65, 228-235

Smorag Z., Gajda B., 1998. In vitro and in vivo survival of rabbit embryos vitrified in EFS medium and increased PBS salt concentration. Cryo-Lett. 19, 99-104

Smorag Z., Wierzbowski S., Wierzchoś E., Kareta W., Gajda B., 1977. Results of transplanting frozen sheep embryos (in Polish). Med. wet. 33, 552-555

Somfai T., Dinnyes A., Sage D., Marosan M., Carnwath J.W., Ozawa M., Kikuchi K., Niemann H., 2006. Development to the blastocyst stage of parthenogenetically activated in vitro matured porcine oocytes after solid surface vitrification (SSV). Theriogenology 66, 415-422

Somfai T., Kashiwazaki N., Ozawa M., Nakai M., Maedomari N., Noguchi J., Kaneko H., Nagai T., Kikuchi K., 2008. Effect of centrifugation treatment before vitrification on the viability of porcine mature oocytes and zygotes produced in vitro. J. Reprod. Develop. 54, 149-155

Sommerfeld V., Niemann H., 1999. Cryopreservation of bovine in vitro produced embryos using ethylene glycol in controlled freezing or vitrification. Cryobiology 38, 95-105

Suzuki C., Yoshioka K., 2006. Effects of amino acid supplements and replacement of polyvinyl alcohol with bovine serum albumin in porcine zygote medium. Reprod. Fert. Develop. 18, 789795

Tradi A.S., Leboeuf B., Cognie Y., Poulin N., Mermillod P., 1999. Comparative results of in vitro and in vivo survival of vitrified in vitro produced goat and sheep embryos. Theriogenology 51, 257 (Abstr.)

Ushijima H., Yamakawa H., Nagashima H., 1999. Cryopreservation of bovine pre-morula-stage in vitro matured/in vitro fertilized embryos after delipidation and before use in nucleus transfer. Biol. Reprod. 60, 534-539

Vajta G., Booth P.J., Holm P., Greve T., Callesen H., 1997b. Successful vitrification of early stage bovine in vitro produced embryos with the Open Pulled Straw (OPS) method. Cryo-Lett. 18, 191-195

Vajta G., Holm P., Greve T., 1997a. Vitrification of porcine embryos using the Open Pulled Straw (OPS) method. Acta Vet. Scand. 38, 349-352

Vajta G., Holm P., Greve T., Callesen H., 1996. Overall efficiency of in vitro embryo production and vitrification in cattle. Theriogenology 45, 683-689

Vajta G., Rindom N., Peura T.T., Holm P., Greve T., Callesen H., 1999. The effect of media, serum and temperature on in vitro survival of bovine blastocysts after Open Pulled Straw (OPS) vitrification. Theriogenology 52, 939-948

Willadsen S.M., Polge C., Rowson L.E.A., Moor R.M., 1976. Deep freezing of sheep embryos. J. Reprod. Fertil. 46, 151 (Abstr.)

Wilmut I., Rowson L.E.A., 1973. Experiments on the low-temperature preservation of cow embryos. Vet. Res. 92, 686-690

Yang B.S., Leibo S.P., 1999. Viability of in vitro-derived bovine zygotes cryopreserved in microdrops. Theriogenology 51, 178 (Abstr.) 